Women and men who masturbated were viewed as wasting their bodies and weakening their chances both of conception and carrying a fetus to full term. The idea of connecting poor eyesight and masturbation was published for the first time around this period, as far as I can tell, along with weak teeth, back pain and stooping shoulders.

Man-midwives, known as early as the 17 th century, are by the 18th century even publishing advice books and helping directly with the birthing process. Midwives generally seemed to escape the worst insults thrown at quacks, but there are cases of witchcraft accusations even at this late time.

Contraception is written about as gut condoms, citrus fruit tops and abortion. Gynaecological health was dominated by sexually transmitted diseases, now rampant through all levels of society.

\section{Concluding remarks}

This article can only hope to give a hint of the hilarious range of treatments on offer during this period of history. What one can see, however, amongst the insane and desperate remedies of the time, are glimmers of the thinkers and the scientists we know today, like a light on the horizon.

\section{Future articles}

The next article in this series will be on the controversial topic of Mary Stuart's miscarriage.

\section{Author's note}

In my last article I asked if readers had knowledge of any published information they may have seen relating to female chastity belts. I would like to take this opportunity of thanking all of you who took the trouble to write to me with glimmers of information and some mind-boggling current designs for chastity belts. However, we still have no historical evidence of chastity belts for women.
Acknowledgements

The author would like to thank the following individuals for their help and advice: Professor R Arnott, Director of the Centre for the History of Medicine, University of Birmingham Medical School, Birmingham and Dr G Williams, Curator of the British Museum, London, UK.

Bibliography

1 Porter, Roy. Quacks: Fakers \& Charlatans in Medicine. Stroud, UK: Tempus Publishing Ltd, 2003.

2 Thompson, Charles JS. Quacks of Old London (first published in 1928) Whitefish, MT, USA: Kessinger Publishing, 2003.

3 Hamilton, David. The Healers. Edinburgh, UK: Canongate Publishing Ltd, 1981.

4 Sloan, AW. English Medicine in the Seventeenth Century. Bishop Auckland, UK: Durham Academic Press, 1996.

5 Driver, Christopher and Berriedale-Johnson, Michelle. Pepys at Table. London, UK: Bell \& Hyman, 1984.

6 Herman, Eleanor. Sex with Kings: Five Hundred Years of Adultery, Power, Rivalry, and Revenge. London, UK: Harper Perennial, 2005.

7 Aristotle's Masterpiece (a manual of sex and pregnancy) Unknown author and publisher, circa 1684. (NB. Copies of this book can be found in antiquarian bookshops. Some of the later editions are reasonably priced but the earlier editions with little editing are much more fascinating.)

8 Berry, George. Taverns and Tokens of Pepys' London. London, UK: Seaby Publications Ltd, 1978.

9 Wilson, Derek. All the King's Women: Love, Sex and Politics in the Life of Charles II. London, UK: Pimlico, 2004.

10 Prior, Mary (ed.). Women in English Society 1500-1800. London, UK: Routledge, 1985.

About the author

Lesley Smith is a late-16th century historian, currently studying for the degree of MPhil in the History of Medicine at Birmingham University Medical School (and waiting to see if her proposal will be accepted as a PhD). During 2007 Lesley has appeared in television programmes on the east and west coasts of America, Transylvania and England. She is currently advising on a Tudor documentary for the BBC as a medical historian. She has also recently joined the debate on BBC radio about legalisation of brothels - a debate stimulated by the National Federation of Women's Institutes.

\title{
Raising interest in Contraception and Sexual Health: Special Study Modules for medical students
}

\section{Christina Fey, Chloe Evans}

\section{The problem}

Getting the balance correct in medical workforce planning, particularly in Obstetrics and Gynaecology (O\&G), has been a problem for a number of years. Over the last 10 years, training numbers have varied and the balance between trainees qualified and number of consultant posts available has wavered. Bearing in mind the Government's aims for a consultant-delivered service, and the need for future increase in senior posts (another discussion entirely

J Fam Plann Reprod Health Care 2008; 34(1): 64-65 (Accepted 14 February 2007)

Derby City PCT, Department of Contraception and Sexual Health, Wilderslowe, Derby, UK

Christina Mary Fey, MBChB, MRCOG, Consultant

University of Nottingham Medical School, Faculty of Medicine and Health Services, Queens Medical Centre, Nottingham, UK Chloe Miranda Evans, PhD, Medical Student

Correspondence to: Dr Christina Fey, Derby City Primary Care Trust, Department of Contraception and Sexual Health, Wilderslowe, 121 Osmaston Road, Derby, Derbyshire DE1 2GA, UK. E-mail: christina.fey@derbycitypct.nhs.uk around consultants vs non-consultant senior grade!), we are now seeing the possibility of failure to provide enough trainees to fill anticipated posts. In particular, there are notably fewer trainees attracted to $O \& G$, and we see parallel problems in recruiting to Contraception and Sexual Health (C\&SH). Even now we have unfilled consultant and trainee posts throughout the country (see Workforce Planning Committee reports) $)^{1,2}$ and attracting trainees to our speciality remains a challenge.

A recent survey in the British Journal of Obstetrics and Gynaecology ${ }^{3}$ looked at the main career choices made by medical students and newly qualified doctors and ascertained what factors influenced choice of career. In the first year after graduation the most important factors were experience of their chosen subject as a student, a particular teacher or department, and a doctor's enthusiasm for, and commitment to, the speciality. There were also noticeable differences between different medical schools and choices of career.

Higham, in another article in the same journal, noted changes in medical school curriculum planning over the last 15 years. ${ }^{4}$ There is less time dedicated to O\&G and a teaching block is often shared with other related 
disciplines. In the case of $\mathrm{C} \& \mathrm{SH}$ this is, of course, a bonus. There is a decreasing pool of traditional medical (consultant) teachers and a change in approach to a range of other skilled professionals being involved. The increasing number of students has put pressure on existing training facilities, with subsequent reduction in hands-on and practical experience.

\section{One possible solution}

The General Medical Council (GMC), in its document Tomorrow's Doctors, 5 states that a Student Selected Component (SSC) should support the core curriculum and allow students to: gain and develop knowledge, skills and abilities in research and new areas of interest; develop greater confidence in their own skills and abilities; present the results of their work and consider potential career paths.

The Special Study Module (SSM), equivalent to the SSC, component of the course at Nottingham University Medical School is a 4-week placement that occurs in both the fourth and final years, within a particular branch of medicine in which students have a special interest. The choice of SSM is limited by the number of departments prepared to offer a placement and by the number of students competing for places. Within these constraints, however, the choice is the students' preference.

Derby Contraception and Sexual Health Service was approached to provide placements for the Nottingham students, since we have been providing introductory experience in C\&SH for students in their community week for some time.

The aims were to offer a broader experience in contraception and related sexual health disciplines, enabling the student to achieve those aims documented in Tomorrow's Doctors. 5

\section{The outcome}

Our allocated medical student, Chloe, identified the areas she would particularly like to experience and we designed her programme accordingly.

Chloe responded very well to the challenges of working/studying within the team and without exception was a popular addition to each clinic. She brought a mature and experienced approach to her audit project, which has provided useful information and impetus to improve our unplanned pregnancy service. Her description (see below) of her experiences was extremely encouraging for all concerned.

We will be seeing more students for their SSM and would highly recommend the practice to others.

\section{The student's perspective}

During the winter of 2006, I spent 4 weeks with the C\&SH service in Derby as my final-year SSM. My interest in C\&SH before I began the placement was largely down to my belief that I would eventually become a general practitioner at the end of my training and thus the consequent importance of having good knowledge and skills in this area. I was also strongly influenced by how keen the doctors working in C\&SH were to help me organise an SSM to work with them. Due to burgeoning student numbers, being made so welcome was not a common experience during my time in clinical training.

The placement itself was in Derby and surrounding areas, and I took part in a variety of activities over the 4 weeks. Predominantly I spent my time attending C\&SH clinics; however, these varied widely from traditional family planning, to youth clinics with a stronger emphasis on sexual health and safe sex, to clinics in areas with a high proportion of black and ethnic minority clients.
Additionally, I attended clinics in the genitourinary medicine service, both with doctors and health advisors, sat in with the HIV specialist nurses, and attended an HIV clinic and multidisciplinary team meeting. I also spent some time with the Teenage Pregnancy Co-ordinator for Derby and gained a good understanding of the variety of services available to help prevent teenage pregnancy and support young mothers once they have had their babies. When not attending clinics, I carried out a small retrospective audit of attendance at $\mathrm{C} \& \mathrm{SH}$ for follow-up post-termination of pregnancy (TOP) and contraception post-TOP, which I found interesting and stimulated me to read more about the subject.

The time I spent with C\&SH in Derby has been some of the most enjoyable of my career as a medical student to date. It has made me think again about a career in $\mathrm{O} \& \mathrm{G}$, which I had previously rejected, and has given me a good idea of what training would be required to work in C\&SH. It has been interesting to spend time with a number of doctors who have arrived at jobs in C\&SH through quite different routes and hear about how their careers have progressed. It has been a very positive experience to speak to doctors who are universally enthusiastic about their jobs despite budgetary and other constraints on their service.

My knowledge of the field of $\mathrm{C} \& \mathrm{SH}$ has naturally expanded and it was interesting to learn more about the clinical aspects of contraception and sexually transmitted infections and to be able to add to what was taught in $\mathrm{O} \& \mathrm{G}$, and I have now consolidated a solid foundation in this area. However, I feel I benefited most in terms of learning in the area of communication skills. The consultations I observed in C\&SH contained excellent examples of best practice in many areas that the medical school teaches us via role-playing, such as empathy, rapport, active listening and responding, and giving explanations supported by literature to take away. Seeing these skills used in real-life situations has been invaluable to me. All the consultations I observed, whether undertaken by doctors or others, contained elements that I will try to incorporate into my own practice in the future.

The highlight of the placement was the final week in which the doctors and nurses were kind enough to trust me sufficiently to let me loose on their patients on my own. I very much enjoyed talking to all the women, and it helped me develop and practise all the skills that I had observed others using throughout the previous weeks. After a few consultations I felt much more confident and my examination skills improved exponentially. For me, therefore, my placement ended on a real high and I would encourage any student who is interested in this area to seek out someone with whom to develop a similar SSM.

\section{References}

1 Faculty of Family Planning and Reproductive Health Care of the Royal College of Obstetricians and Gynaecologists. The Seventh \& Eighth Census of the Family Planning Workforce in the United Kingdom 2003 \& 2004. http://www.fsrh.org/ admin/uploads/census0304.pdf [Accessed 12 February 2007].

2 Faculty of Family Planning and Reproductive Health Care of the Royal College of Obstetricians and Gynaecologists. The Ninth \& Tenth Census of the Family Planning Workforce in the United Kingdom 2005 \& 2006. http://www.fsrh.org/admin/ uploads/Census0506.pdf [Accessed 12 February 2007].

3 Turner G, Lambert TW, Goldacre MJ, Barlow D. Career choices for obstetrics and gynaecology: national surveys of graduates 1974-2002 from UK medical schools. Br J Obstet Gynaecol 2006; 113: 350-356.

4 Higham J. How can we make our medical students enthusiastic about a future in obstetrics and gynaecology? $\mathrm{Br} J$ Obstest Gynaecol 2006; 113: 499-501.

5 General Medical Council. Tomorrow's Doctors. February 2003 http://www.gmc-uk.org/education/undergraduate/ GMC_tomorrows_doctors.pdf [Accessed 12 February 2007] 